Ewa Płonowska ${ }^{1}$, Inna Diemieszczyk ${ }^{1}$, Krystian Ejdys $^{1}$, Alicja Jelska ${ }^{1}$, Andrzej Chomentowski ${ }^{1}$, Paulina Głuszyńska ${ }^{1}$, Marzena Wojewódzka-Żelazniakowicz ${ }^{2}$, Klaudiusz Nadolny ${ }^{3}, 4$, Jerzy R. Ładny ${ }^{1,2}$, Hady Razak Hady ${ }^{1}$

${ }_{1}^{1} 1^{\text {st }}$ Department of General and Endocrine Surgery, Medical University of Bialystok, Poland

${ }^{2}$ Department of Emergency and Disaster Medicine, Medical University of Bialystok, Poland

${ }^{3}$ Faculty of Medicine, Katowice School of Technology, Katowice, Poland

${ }^{4}$ Department of Health Sciences, WSB University, Dabrowa Gornicza, Poland

\title{
The influence of COVID-19 pandemic on number of patients reporting to the Emergency Department and operated of acute cholecystitis and incarcerated hernias
}

\author{
Corresponding author: \\ Ewa Płonowska, $1^{\text {st }}$ Department \\ of General and Endocrine Surgery, \\ Medical University of Bialystok \\ M. Sklodowskiej-Curie 24a Str., \\ 15-276 Bialystok, Poland; \\ e-mail: ewaplonowska11@wp.pl
}

Medical Research Journal 2022; Volume 7, Number 1, 17-23 DOI: 10.5603/MRJ.a2022.0004 Copyright (C) 2022 Via Medica ISSN 2451-2591 e-ISSN 2451-4101

\begin{abstract}
Introduction: The fear of SARS-CoV-2 infection had a significant impact on a number of patients reporting to the hospitals. Despite the presence of disturbing symptoms, patients postponed their medical visits. It resulted in health deterioration that worsened conditions for surgical procedures.

Aim of the study: The aim of study was to analyze the impact of the COVID-19 pandemic on a number of patients reporting to the Emergency Department at University Hospital in Bialystok and a number of surgical emergency procedures and the Department of General Surgery.

Material and methods: The retrospective analysis of patients who reported to the Internal Medicine and Surgical office of the Emergency Department at University Hospital in Bialystok in the same periods from June to December 2019 and 2020 with surgical conditions such as cholecystitis, inguinal hernia, and umbilical hernia.

Results: In 2020, there was a significant decrease in the number of patients reporting to the Emergency Department when compared to 2019 (664 vs. 955). In 2020, there were more emergency surgeries performed including laparoscopic cholecystectomy (32 vs. 28) and inguinal hernia repair (17 vs. 5, $p=0.0013$ ) compared to 2019. The analysis of biochemical parameters showed a higher level of C-reactive protein in patients undergoing emergency surgery in 2020 when compared to 2019 (11.85 vs. $3.35 p=0.0140$ ). Conclusions: The number of patients reporting to the Emergency Department was significantly lower in 2020 when compared to 2019 and patients presented more severe symptoms and general conditions. The above analysis triggered by the Coronavirus pandemic could be a useful tool for better managing similar crisis in the future.
\end{abstract}

Key words: COVID-19, SARS-CoV-2, pandemic, emergency surgical procedure

Med Res J 2022; 7 (1): 17-23

\section{Introduction}

Coronavirus disease 2019 (COVID-19) is caused by the severe acute respiratory syndrome coronavirus 2 (SARS-CoV-2) and belongs to the Coronaviridae family of the $\beta$-coronavirus group [1]. The first cases of pneumonia caused by a previously unknown pathogen were detected in the Chinese city of Wuhan in Hubei province on November 17, 2019. Due to the spread of the virus by airborne droplets, the new disease very quickly expanded to new areas and crossed China. In a short time, the appearance of the SARS-CoV-2 affected almost every aspect of people's lives around the world. Viral incubation lasts 2 to 14 days, average -5 days [2]. The 
virus is mainly concentrated in the lungs and respiratory tract, however, the SARS-CoV-2 virus can also affect the nervous system, digestive and urinary systems, as well as vessels and the heart. The dominant symptoms of COVID-19 are fever, cough, fatigue, as well as loss of smell and taste [3]. Most cases of COVID-19 are mild $(81 \%)$. Severe cases requiring treatment in intensive care units accounted for $14 \%$, and critical cases for $5 \%$ [4]. The elderly, subjects with cardiovascular diseases and respiratory diseases (especially chronic obstructive pulmonary disease - COPD), patients with active neoplastic disease, diabetes, obese patients, and smokers are particularly at risk of developing complications [5].

The spreading of new disease (COVID-19) has greatly reduced daily activities of millions of people of all ages, causing the necessity to stay at home and limit social interactions. The first coronavirus infection in Poland was recorded on March 4, 2020.

To prevent the spread of the virus, special sanitary recommendations have been introduced in Poland, including protective masks, hands and frequently touched surfaces disinfection. In addition, restrictions for service premises and limited number of people in public places were applied. Remote learning and work were also intended to reduce the number of infections. In order to ensure access to specialist medical care, with the constantly growing number of patients, some departments and hospitals have been transformed into centers dedicated to the treatment of people infected with the SARS-CoV-2.

The unusual situation related to the appearance of the SARS-CoV-2 virus influenced patients reporting to medical facilities. The fear of infection was often the cause of ignoring the disturbing symptoms, and thus delaying consultation with a specialist or resignation from visiting a physician if the patient decided that his condition was not serious [6]. This situation contributed to changes in the number of diseases, so far the most commonly observed in hospital emergency departments, clinics, and hospitals.

The functioning of the operating theater has also changed. Planned surgical procedures were postponed. Before admission to the surgical department, each patient admitted to the University Hospital in Bialystok was tested for SARS-CoV-2. Due to the presence of the virus in body fluids and its spread via droplets, the personnel present in the operating room was advised to use barrier gowns, FFP3 masks and visors - in accordance with sanitary and epidemiological hospital standards. It was also recommended to change the operating technique to minimize aerosol spreading [7-9].

In this study, we investigated the influence of pandemic on the number of patients reporting to the Emergency Department. The parameters of patients' laboratory tests and the clinical condition in the period before and during the COVID-19 pandemic were compared.
The study also shows how the COVID-19 pandemic affected the number of hospitalizations and operations in comparison to the period before the pandemic. In this study, we focused on the most frequently diagnosed diseases at the Emergency Department of the University Hospital in Bialystok, that is acute cholecystitis, inguinal and umbilical hernias.

\section{Material and methods}

The retrospective analysis included patients who reported to the Internal Medicine and Surgical office of the Emergency Department at University Hospital in Bialystok in the same periods from June to December 2019 and 2020.

\section{Data collection}

Patients who were considered on the basis of the medical records of the Emergency Department were patients with the following diagnoses according to the international classification of diseases: ICD-10: R10 (abdominal and pelvic pain); K40 (inguinal hernia); K41 (femoral hernia); K42 (umbilical hernia); K43 (ventral hernia); K44 (Diaphragmatic hernia); K80 (cholelithiasis); K81 (cholecystitis); K82 (other diseases of the gallbladder); K83 (other diseases of biliary tract); K87 (disorders of gallbladder, biliary tract, and pancreas in diseases classified elsewhere). In 2019, 955 patients (mean age $50.52 \pm 20.94$ years; $57.07 \%$ women) were included, while in $2020-664$ patients (mean age $52.63 \pm 19.33$ years; $57.23 \%$ women). Afterwards, all patients were checked in the hospital information system whether they had been admitted to the department and whether they had undergone surgical procedures: cholecystectomy in the case of acute cholecystitis or inguinal, femoral, umbilical, abdominal or diaphragmatic hernia surgery. Every patient underwent basic laboratory tests, for the purpose of statistical analysis. The parameters considered were: the number of leukocytes, erythrocytes, platelets, hemoglobin, total bilirubin, C-reactive protein (CRP), the activity of alanine (ALAT), and aspartate (ASPAT) transaminase. All patients diagnosed with R10 (pain in the abdominal and pelvic area) in the Emergency Department were checked in the hospital information system whether they were admitted to other hospital departments or later admitted to the departments of the University Hospital in Bialystok on a scheduled basis and what was the final diagnosis for those patients.

\section{Statistical methods}

Data was statistically analyzed using GraphPad Prism 8.0 (GraphPad Software Inc.). The Shapiro-Wilk test was used to determine the normality of the distribu- 
tion of quantitative data (age at admission, laboratory parameters). Data without normal distribution were compared using $U$ Mann-Whitney test, while data with normal distribution was analyzed with T-test for independent samples. The analysis of qualitative data regarding the frequency of particular diagnosis in the Emergency Department and the frequency of urgent operations performed in the Department of General and Endocrinological Surgery was conducted using the Fisher exact test or - in the case of observed counts $<10-$ Chi-square independence test with Yates correction for continuity. Values of $p<0.05$ were considered statistically significant.

\section{Results}

In 2019, the study group consisted of 955 subjects (mean age $50.52 \pm 20.94$, median 49 years; $57.07 \%$ women), while in 2020 - 664 patients (mean age $52.63 \pm 19.33$, median 54 years; $57.23 \%$ women), the age difference is statistically significant $(p=0.026)$.

Though both, in the group of women and men, the number in 2020 decreased in comparison to 2019, the percentage of women and men remained at a similar level (Tab. 1). Diagnoses K40 (inguinal hernia) and K80 (cholelithiasis) were registered statistically significantly more often in 2020 than in 2019 (28 vs. 21, $p=0.0272 ; 125$ vs. $104, p=0.0001)$. In the case of the other analyzed ICD 10 codes, no statistically significant differences were found (Tab. 2).

In 2020, in comparison to 2019, more emergency laparoscopic cholecystectomies (32 vs. 28) and inguinal hernia operations ( 17 vs. $5 ; p=0.0013-$ a significant increase in frequency) (Fig. 1).
The analysis of the further actions of patients revealed that in most cases, in 2020, fewer diagnoses were made in comparison to 2019 , and in the case of the $\mathrm{N} 20$ code (ureterolithiasis) the difference is statistically significant ( $p=0.0329$ ) (Tab. 3).

The analysis of laboratory test results showed significantly higher concentrations of C-reactive protein in patients undergoing acute surgery in 2020, compared to 2019 (11.85 vs. $3.35 ; p=0.014)$. Other parameters remained at a similar level in both analyzed periods (Tab. 4).

\section{Discussion}

Basing on the analysis conducted in own material, it was found that in 2020 , compared to 2019 , more emergency laparoscopic cholecystectomies and inguinal hernia operations were performed. The reason for this may be the fact that patients afraid of coronavirus infection in the Emergency Department, did not report symptoms for a long time, trying to deal with the disease

Table 1. Demographic characteristics of the study group

\begin{tabular}{lcc}
\hline & $\mathbf{2 0 1 9}$ & $\mathbf{2 0 2 0}$ \\
\hline Age & & \\
Mean [years] & 50.5 & 52.6 \\
Median & $49(18-98)$ & $50(18-95)$ \\
Gender & & \\
Women & $545(57 \%)$ & $380(57 \%)$ \\
Men & $410(43 \%)$ & $284(43 \%)$ \\
Total & 955 & 664 \\
\hline
\end{tabular}

Table 2. Emergency room (ER) diagnoses; comparison of 2019 and 2020

\begin{tabular}{lccccc}
\hline Diagnosis according to ICD-10 & $\mathbf{2 0 1 9}$ & \% of total & $\mathbf{2 0 2 0}$ & \% of total & P-value \\
\hline R10 - abdominal and pelvic pain & 780 & 81.7 & 482 & 50.5 & 0.1346 \\
K40 - inguinal hernia & 21 & 2.2 & 28 & 2.9 & 0.0272 \\
K41 - femoral hernia & 1 & 0.1 & 2 & 0.2 & 0.7527 \\
K42 - umbilical hernia & 13 & 1.4 & 4 & 0.4 & 0.2259 \\
K43 - abdominal hernia & 5 & 0.5 & 3 & 0.3 & 0.8738 \\
K44 - diaphragmatic hernia & 2 & 0.2 & 2 & 0.2 & 0.8856 \\
K80 - cholelithiasis & 104 & 10.9 & 125 & 13.1 & 0.0001 \\
K81 - cholecystitis & 14 & 1.5 & 6 & 0.6 & 0.4431 \\
K82 - other gallbladder diseases & 4 & 0.4 & 4 & 0.4 & 0.8767 \\
K83 - other diseases of the biliary tract & 11 & 1.2 & 6 & 0.6 & 0.8188 \\
K87 - disorders of gallbladder, biliary tract and & 0 & 0 & 2 & 0.2 & 0.3293 \\
pancreas in diseases classified elsewhere & & & & &
\end{tabular}


at home [10]. When the symptoms intensified, patients reported to the hospital in a condition requiring urgent admission and rapid surgical intervention.

Patients reported in advanced stage of the disease, therefore, the operations were technically more difficult and accompanied by a greater number of intraoperative complications [11]. It is evident in the statistical difference in the inflammation index (C-reactive protein concentration). The increase in the number of

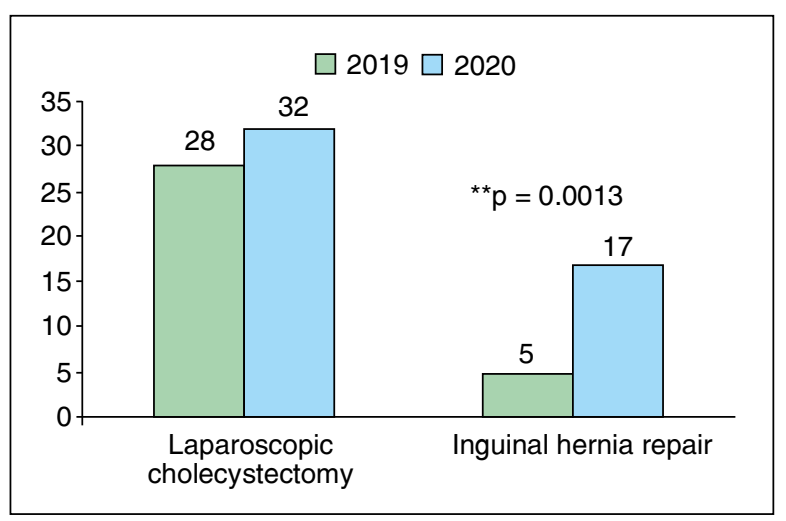

Figure 1. Comparison of the number of urgent operations performed at the General Surgery Department 2019-2020 performed surgical procedures was observed at the University Hospital in Bialystok. Whereas in other centers in the country and around the world, a decrease in the number of procedures performed due to the COVID-19 pandemic was observed. In Auckland City Hospital, comparing the period of the first lockdown on March 26 - April 27, 2020, to the corresponding 33 days before the lockdown (February 22 - March 25, 2020), the number of operations performed decreased by $43.6 \%$ [12]. At Bakirkoy Dr. Sadi Konuk Training and Research Hospital in Istanbul, in the period from March 14 to May 14, 2020, there was a $59.1 \%$ decrease in the number of urgent surgical procedures compared to the same period in 2019. What is more, a decrease in admissions for patients with acute cholecystitis by $47.3 \%$ was observed, as well as, 92\% decrease for patients with an incarcerated hernia [13]. In a multicenter retrospective study of three hospitals of III referral level in Spain during the lockdown period from March 16 to April 26, 2020, 117 emergency surgeries (29.1\%) were performed, while 285 such procedures were performed between March 11 and April 21, 2019 (70.9\%). The number of procedures for acute cholecystitis during the pandemic decreased $(12.3 \%-2019 ; 2.6 \%-2020)$, while the number of hernia surgeries increased $(5.6 \%-2019$; $9.4 \%-2020$ ) [10]. The increase in the number of hernia

Table 3. Further actions of patients — final diagnoses made in patients admitted with the R10 code; 2019 vs. 2020 comparison

\begin{tabular}{llccc}
\hline ICD -10 diagnosis & $\mathbf{2 0 1 9}$ & $\mathbf{2 0 2 0}$ & P-value \\
\hline R10 & Abdominal and pelvic pain & 486 & 323 & 0.4326 \\
K29 & Gastroduodenitis & 41 & 14 & 0.0644 \\
K80 & Cholelithiasis & 22 & 18 & 0.4111 \\
N39 & Other urinary diseases & 22 & 5 & 0.0593 \\
N20 & Ureterolithiasis & 19 & 3 & 0.0329 \\
K59 & Other functional bowel disorders & 17 & 3 & 0.0588 \\
K85 & Acute pancreatitis & 17 & 8 & 0.6719 \\
K35 & Acute appendicitis & 14 & 5 & 0.4119 \\
K56 & Paralytic ileus and intestinal obstruction without hernia & 12 & 11 & 0.3894 \\
K52 & Other non-infectious gastro-intestinal catarrh and colitis & 11 & 8 & 0.9121 \\
N23 & Undefined renal colic & 10 & 3 & 0.4066 \\
K57 & Diverticulosis & 9 & 11 & 0.1932 \\
K86 & Other diseases of pancreas & 9 & 3 & 0.5234 \\
K26 & Duodenal ulcer disease & 6 & 0 & 0.1333 \\
K76 & Other diseases of liver & 6 & 8 & 0.2406 \\
D37 & Tumor with uncertain or unknown origin in mouth and gastrointestinal organs & 5 & 7 & 0.2586 \\
A09 & Diarrhea or gastrointestinal inflammation with a possible infectious origin & 4 & 1 & 0.7079 \\
K65 & Peritonitis & 4 & 2 & 0.8597 \\
& Total & 780 & 482 & \\
\hline
\end{tabular}


Table 4. Laboratory parameters of operated patients in urgent condition*

\begin{tabular}{|c|c|c|c|}
\hline & 2019 & 2020 & P-value \\
\hline WBC & $\begin{array}{c}7.86(5.93-9.22) \\
N=42\end{array}$ & $\begin{array}{c}7.610(5.56-10.44) \\
N=49\end{array}$ & 0.8913 \\
\hline CRP & $\begin{array}{c}3.35(1.50-13.28) \\
N=34\end{array}$ & $\begin{array}{c}11.85(3.50-160.3) \\
N=30\end{array}$ & 0.0140 \\
\hline RBC & $\begin{array}{c}4.70(4.18-5.22) \\
N=42\end{array}$ & $\begin{array}{c}4.60(4.11-5.10) \\
N=49\end{array}$ & 0.3462 \\
\hline HGB & $\begin{array}{c}14.06(12.55-15.57) \\
N=42\end{array}$ & $\begin{array}{c}13.77(12.26-14.58) \\
N=49\end{array}$ & 0.3592 \\
\hline PLT & $\begin{array}{c}265.30(190.79-339.81) \\
N=42\end{array}$ & $\begin{array}{c}242.10(176.54-307.66) \\
N=49\end{array}$ & 0.1187 \\
\hline ASPAT & $\begin{array}{c}34.00(24.25-52.00) \\
N=18\end{array}$ & $\begin{array}{c}31.00(22.25-44.75) \\
N=28\end{array}$ & 0.7847 \\
\hline ALAT & $\begin{array}{c}31.50(17.50-45.00) \\
N=24\end{array}$ & $\begin{array}{c}34.00(18.25-56.00) \\
N=28\end{array}$ & 0.4913 \\
\hline BIL-T & $\begin{array}{c}1.04(0.710-2.21) \\
N=27\end{array}$ & $\begin{array}{c}0.84(0.59-1.52) \\
N=29\end{array}$ & 0.3178 \\
\hline
\end{tabular}

*The results of parameters with a normal distribution (RBC, HBG, PLT) are presented as the mean and the range of the standard deviation. For parameters with no normal distribution (WBC, CRP, ASPAT, ALAT, BIL-T) the results are expressed as median and a quarter range; ALAT alanine aminotransferase; ASPAT — aspartate aminotransferase; BIL-T — total bilirubin; CRP — C-reactive protein; HBG — haemoglobin; PLT — platelet count; RBC — red blood cell; WBC — white blood cell

surgeries in our study and Spanish researchers confirms the hypothesis that the possibility of conservative treatment due to coronavirus in case of hernia is limited and clinical condition of the patients is more severe when they report to the Emergency Department and they require urgent surgical intervention. The reason for the higher number of cholecystectomies performed in 2020 may be the deteriorating quality of patients' diet during the lockdown period. The results of the survey of researchers from Poznan showed that during the national quarantine, $43.5 \%$ of respondents declared that they consumed more food than before the pandemic, and $51.8 \%$ of respondents admitted eating snacks between meals. Moreover, one-third of the respondents did not eat fresh fruit and vegetables, and one-third of the respondents consumed sugar confectionery at least once a day [14]. The anonymous online survey concerning the eating habits of Poles during the pandemic showed that $40 \%$ of the surveyed men and almost half of the surveyed women have significantly gained body mass, and therefore their BMI also increased. The study also revealed, that during isolation both women and men significantly more often consumed products containing an increased content of saturated fatty acids (canned meat) [15]. A survey conducted among Polish university students showed that $71.94 \%$ of the study participants have seen the negative impact of the pandemic on their physical activity. Moreover, 51.02\% of respondents indicated that the COVID-19 pandemic had an adverse effect on their eating habits [16]. Eating foods with high content of saturated fatty acids, fast food or sugar confectionery significantly increases the risk of gallstone disease, and as a complication - acute cholecystitis [17]. Self-treatment had a particular impact on the number and health condition of patients who reported for consultations in the Emergency Department. The cause of this phenomenon may be connected with the difficult access to a general practitioner, fear of contracting the SARS-CoV-2 virus in medical facilities, and related quarantine as well as limitation of earning capacity [18].

The survey conducted by Ewa Palinska [19] was designed to examine whether Polish patients are afraid of being infected with the SARS-CoV-2 virus during a visit to medical facility. As many as $28 \%$ of respondents avoided consulting a doctor because of fear of infection; $28 \%$ of respondents admitted that they would see a doctor if they needed help. Other subjects participating in the study believed that medical facilities were safe $(34 \%)$ or did not care about the possibility of infection (10\%). Fear of infection was the main reason for taking medication inappropriately - consuming medications to improve physical and mental health, taking "prophylactic" medications, taking prescription medications without consulting a specialist. Self-treatment and postponing a consultation with a physician despite disturbing symptoms were extremely dangerous behavior; the results of the study revealed that as many as $42 \%$ of respondents admitted to such actions [6]. The aforementioned behaviors caused delayed 
reporting to the doctor's office, in worse condition, the diseases were in more advanced stage, the treatment was more difficult, and carried a higher risk of complications. This corresponds to the results obtained in our study, especially the increased values of C-reactive protein in 2020 compared to 2019.

The higher number of emergency surgeries may result from the conversion of some hospitals or departments into centers dedicated only to the treatment of patients infected with the SARS-CoV-2 virus. In Podlasie, surgical departments were transformed into COVID departments at SPZOZ MSWiA in Bialystok, SPZOZ in Bielsk Podlaski, SPZOZ in Lomza, and SPZOZ in Sokołka. A study by A. Kasiukiewicz and Z. Wojszel [20] showed that in the period from April 14 to August 14, 2020, 135 patients were hospitalized at SPZOZ MSWiA in Bialystok, while in the same period in 2019 the number of patients admitted was 2,444 . The exclusion of aforementioned centers from their basic tasks could lead to the situation when patients started to seek medical help in other hospitals, which would explain the greater number of cholecystectomies and inguinal hernia operations performed at the $1^{\text {st }}$ Department of General and Endocrine Surgery in Bialystok in 2020 than in 2019.

The COVID-19 pandemic has turned telemedicine into a tool commonly used by patients. Contact with a doctor became easier - it saved patients' time and costs related to travel; it enabled doctors to admit more patients in a shorter period of time [21]. Patients were more eager to seek advice, and as a result, it was easier to obtain prescription drugs without direct contact with a doctor, therefore the phenomenon of self-treatment was often observed. Almost half of the respondents (45.6\%) admitted to at least one inappropriate behavior related to self-treatment during the lockdown, e.g. $16.6 \%$ of the respondents took preventive drugs, and $16.8 \%$ of the respondents took previously obtained drugs without medical consultation [6]. The phenomenon of self-treatment carries many dangers, such as incorrect self-diagnosis, and thus inappropriate selection of therapy; side effects of inappropriately taken medications; taking unproper doses of drugs; the risk of addiction or inappropriate storage of drugs, which may change their activity [22]. The phenomenon of self-treatment delayed the patient seeking medical advice and, consequently, increased reporting to the ERs.

The crisis related to the pandemic and the fact that admitting patients with COVID-19 requires a reorganization of hospital work resulted in numerous cancellations of planned surgeries. In the Krakow Hospital in Kliny, within a week of the first case of coronavirus infection in Poland, the admissions of patients were reduced by approximately $50 \%$, and in the following weeks by $70 \%$. Similar actions were taken in most of the institutions in the country, both operating in the public and private sectors [23]. Postponing so many operating procedures will result in overlapping dates of planned procedures and additionally - increased costs for the healthcare system. Diseases will be treated in a more advanced stage, which will require higher treatment costs and intensive care. The above statements are reflected in the results of our study - the number of acute ER patients.

\section{Conclusions}

Based on the results from our center as well as national and world data, it can be concluded that in 2020 , compared to 2019 , the number of patients reporting to the Emergency Department was significantly lower. In addition, the statistically significant increase in the inflammatory markers was seen in patients operated in urgent conditions in $\mathbf{2 0 2 0}$ when compared to 2019. This fact could be a result of many factors, such as, fear of going to the hospital and getting infected with coronavirus, cancellation of scheduled operations, inadequate quality of the patients' diet, self-treatment, transforming some hospitals or departments into centers for treating patients infected with SARS-CoV-2, medical tele-consultations. Analyzing the causes of changes in the functioning of the healthcare system caused by the coronavirus pandemic will help more efficiently and effectively manage similar crises in the future around the world.

\section{Conflict of interest: None.}

\section{Funding: None.}

\section{References}

1. Synowiec A, Szczepański A, Barreto-Duran E, et al. Severe Acute Respiratory Syndrome Coronavirus 2 (SARS-CoV-2): a Systemic Infection. Clin Microbiol Rev. 2021; 34(2), doi: 10.1128/CMR.00133-20, indexed in Pubmed: 33441314

2. Lauer SA, Grantz KH, Bi Q, et al. The Incubation Period of Coronavirus Disease 2019 (COVID-19) From Publicly Reported Confirmed Cases: Estimation and Application. Ann Intern Med. 2020; 172(9): 577-582, doi: 10.7326/M20-0504, indexed in Pubmed: 32150748.

3. Tong JY, Wong A, Zhu D, et al. The Prevalence of Olfactory and Gustatory Dysfunction in COVID-19 Patients: A Systematic Review and Meta-analysis. Otolaryngol Head Neck Surg. 2020; 163(1): 3-11, doi: 10.1177/0194599820926473, indexed in Pubmed: 32369429.

4. Wu Z, McGoogan JM. Characteristics of and Important Lessons From the Coronavirus Disease 2019 (COVID-19) Outbreak in China: Summary of a Report of 72314 Cases From the Chinese Center for Disease Control and Prevention. JAMA. 2020; 323(13): 1239-1242, doi: 10.1001/jama.2020.2648, indexed in Pubmed: 32091533.

5. Setiati S, Harimurti K, Safitri ED, et al. Risk factors and laboratory test results associated with severe illness and mortality in COVID-19 patients: A systematic review. Acta Med Indones. 2020; 52(3): 227-245, indexed in Pubmed: 33020334

6. Makowska M, Boguszewki R, Nowakowski M, et al. Self-Medication-Related Behaviors and Poland's COVID-19 Lockdown. Int J Environ Res 
Public Health. 2020; 17(22), doi: 10.3390/ijerph17228344, indexed in Pubmed: 33187315.

7. Mitura K, Myśliwiec P, Rogula W, et al. In pursuit of COVID-19 surgical risk stratification to manage a limited workforce and supplies in minimally invasive surgery. Wideochir Inne Tech Maloinwazyjne. 2020; 15(3): 416-423, doi: 10.5114/wiitm.2020.95073, indexed in Pubmed: 32904725.

8. Mitura K, Myśliwiec P, Rogula W, et al. Guidelines for the management of surgical departments in non-uniform hospitals during the COVID-19 pandemic. Pol Przegl Chir. 2020; 92(2): 48-59, doi: 10.5604/01.3001.0014.1039, indexed in Pubmed: 32312919.

9. Rymarowicz J, Pędziwiatr M, Major P, et al. How we prepared our operating theatre for patients with SARS-CoV-2 virus. Wideochir Inne Tech Maloinwazyjne. 2021; 16(1): 117-122, doi: 10.5114/witm.2020.95090, indexed in Pubmed: 33786124.

10. Cano-Valderrama O, Morales X, Ferrigni CJ, et al. Acute Care Surgery during the COVID-19 pandemic in Spain: Changes in volume, causes and complications. A multicentre retrospective cohort study. Int Surg. 2020; 80: 157-161, doi: 10.1016/j.ijsu.2020.07.002, indexed in Pubmed: 32679205.

11. Kwiatkowska J. Przez wirusa pacjenci boja się zgłaszać do szpitala. „Choroby nie mogą czekać!”. https://krosno24.pl/informacje/przez-wirusa-pacjenci-boja-sie-zglaszac-do-szpitala-choroby-nie-mogaczekac-i6330 (16.11.2021).

12. McGuinness MJ, Hsee Li. Impact of the COVID-19 national lockdown on emergency general surgery: Auckland City Hospital's experience. ANZ J Surg. 2020; 90(11): 2254-2258, doi: 10.1111/ans.16336, indexed in Pubmed: 32940409.

13. Surek A, Ferahman S, Gemici E, et al. Effects of COVID-19 pandemic on general surgical emergencies: are some emergencies really urgent? Level 1 trauma center experience. Eur J Trauma Emerg Surg. 2021; 47(3): 647-652, doi: 10.1007/s00068-020-01534-7, indexed in Pubmed: 33136190

14. Sidor A, Rzymski P. Dietary Choices and Habits during COVID-19 Lockdown: Experience from Poland. Nutrients. 2020; 12(6), doi: 10.3390/nu12061657, indexed in Pubmed: 32503173.
15. Bolesławska I, Błaszczyk-Bębenek E, Jagielski P, et al. Nutritional behaviors of women and men in Poland during confinement related to the SARS-CoV-2 epidemic. Sci Rep. 2021; 11(1): 19984, doi: 10.1038/s41598-021-99561-w, indexed in Pubmed: 34620981.

16. Jodczyk AM, Gruba G, Sikora Z, et al. PaLS Study: How Has the COVID-19 Pandemic Influenced Physical Activity and Nutrition? Observations a Year after the Outbreak of the Pandemic. Int J Environ Res Public Health. 2021; 18(18), doi: 10.3390/ijerph18189632, indexed in Pubmed: 34574557

17. Di Ciaula A, Garruti G, Frühbeck $G$, et al. The Role of Diet in the Pathogenesis of Cholesterol Gallstones. Curr Med Chem. 2019; 26(19): 3620-3638, doi: 10.2174/0929867324666170530080636, indexed in Pubmed: 28554328.

18. Gawrych M, Cichoń E, Kiejna A. COVID-19 pandemic fear, life satisfaction and mental health at the initial stage of the pandemic in the largest cities in Poland. Psychol Health Med. 2021; 26(1): 107-113, doi: 10.1080/13548506.2020.1861314, indexed in Pubmed: 33300378.

19. Palińska E. Pacjenci odwołuja wizyty u specjalistów, bo boja się lekarzy. https://zdrowie.trojmiasto.pl/Pacjenci-odwoluja-wizyty-u-specjalistowbo-boja-sie-lekarzy-n144804.html (06.10.2021).

20. Kasiukiewicz A, Wojszel ZB. Assessment of Referrals and Hospitalizations in the Hospital Transformed into COVID-19 Facility in Poland during the "Spring Wave" of the Epidemic in 2020-A Cross-Sectional Study. Int J Environ Res Public Health. 2021; 18(13), doi: 10.3390/ijerph18137143, indexed in Pubmed: 34281079.

21. Mills EC, Savage E, Lieder J, et al. Telemedicine and the COVID-19 Pandemic: Are We Ready to Go Live? Adv Skin Wound Care. 2020; 33(8): 410-417, doi: 10.1097/01.ASW.0000669916.01793.93, indexed in Pubmed: 32701252.

22. Ruiz ME. Risks of self-medication practices. Curr Drug Saf. 2010; 5(4): 315323, doi: 10.2174/157488610792245966, indexed in Pubmed: 20615179.

23. Lipiec A. Operacja w czasie epidemii koronawirusa. Kiedy zabieg powinien, a kiedy nie może być odwołany? https://www.medonet. $\mathrm{pl} /$ koronawirus/koronawirus-w-polsce, operacja-w-czasie-epidemiikoronawirusa--kiedy-zabieg-powinien--a-kiedy-nie-moze-bycodwolany-,artykul,63135753.html (16.11.2021) 